\title{
Preface
}

Although virtual worlds remain unstable phenomena a substantial amount of research continues to be undertaken within them and is reflected in the number of disciplines that study them particularly in an interdisciplinary context. Whilst there is already a history of artists investigating new spaces and new technological forms this exploration has continued more recently with sections of the artistic community utilising virtual worlds as a new form, or a new potential artistic space. Established real-world artists have explored virtual worlds as environments for practice and a number of artists and designers have continued to specifically work with Second Life to explore the potential and limitations of the platform

itself. A range of early key works and other recent seminal works produced in Second Life still hold strong to be scrutinised in the context of new technologies and for their contribution in expanding our understanding and experience of virtual space.

\section{THE BACKGROUND}

Second Life remains a virtual world that is not easily defined and understood. Whilst it no longer grabs the populist cultural headlines, as a platform, it has still to be fully understood in terms of its significance within a wider critical discourse of digital and new media art. Further to this the new languages of artistic practice that are being created that are particular to virtual and avatar-mediated worlds are still to be fully defined. This book aims to outline the potential contribution and impact Second Life has had and aims to present a critical framework for the platform and future avatar-mediated virtual worlds through the work of key artists and writers in the field through an articulation of these languages and virtual aesthetics. In itself Second Life may stand the test of time as a continued interface to examine issues of the real and the virtual and may contribute to further theoretical and philosophical discussions of new technologies and artistic practice.

Second Life was initially developed as a commercial venture, and yet was still one of the first virtual worlds to be studied by scholars and educators, and explored by artists and practitioners. Jones notes that, whilst Second Life could not be described as an immersive virtual world based on Heim's set of characteristics of virtual worlds (simulation, interaction, artificiality, immersion, telepresence, full-body immersion, and networked communications), it still sits 'squarely in the discourse of virtual reality because it provides a high level of interactivity and telepresence within a parallel world that allows for the construction of place and self' (Jones, 2006).

Although there has been extensive research in VR and virtual worlds within the humanities and sciences, there has been less research undertaken concerning the use of virtual worlds for creative and 


\section{Preface}

artistic practice. A particular feature of Second Life is the accessibility of the platform for building and customising spaces. Using the Second Life building tools to create objects and manipulate terrain, along with the application of the Second Life programming language, it is possible to have a high level of control when creating a virtual environment. This has enabled a community of artists to take advantage of both the capability and online accessibility of the platform, and of the relatively low cost incurred when compared to that of developing a unique online virtual world from scratch. A question that can be asked is do new forms always bring new modes of practice, and new artistic and creative opportunities? In the context of New Media practice Patrick Lichty proposes that the exploration of new forms has been 'a modus operandi of the avant garde for over a century, and New Media is doubly implicated in this gesture of praxis' (Lichty, 2008). There have been a range of articles published discussing virtual worlds and creative practice developed in Second Life from Backe (2007), McCaw (2007), Bittarello (2008), Sant (2008), Lichty $(2008,2009)$, Morie (2010), each contributing research in the fields of performance, gaming, and the arts. More specifically a number of articles focus on the contextualisation of artistic practice (Doyle 2008, Lichty 2012, Drinkall 2012).

From early writings on virtual reality (such as Damer 1998, Heim 1993, Heudin 1999, Rheingold 1991, Schroeder 2002), to Jones (2006) suggesting that 'virtual reality is the contemporary and future articulation of the philosophical and psychological question of how we define (and create) reality', the issues, definitions and experience of reality find rich and challenging ground in virtual environments. Writing in 2001, Elizabeth Grosz describes virtual realities as: "computer-generated and [computer]-fed worlds that simulate key elements of "real space" or at least its dominant representations - for example, its dimensionality, its relations of resemblance and contiguity - acting as a partial homology for a "real space" within which it is located' (Grosz, 2001).

The early use of virtual environments for artistic practice were explored in a series of projects undertaken at the Banff Centre, Canada, in the early 1990s and subsequently documented in Immersed in Technology: Art and Virtual Environments (Moser 1996). In the preface to that book, Douglas Macleod, the Project Director, likens this 'moment of virtual reality' to a similar moment in time when Vertov's Man with the Movie Camera was released in 1929, cataloguing the potential of the film medium (Macleod in Moser, 1996). Of particular note were works such as Brenda Laurel and Rachel Strickland's Placeholder (1993), the Archaeology of the Mother Tongue (1993) by Toni Dove and Michael Mackenzie, and the virtual reality performance, Dancing with the Virtual Dervish: Virtual Bodies (1994), by Diane Gromala and Yacov Sharir. These projects were particularly innovative in their exploration of virtual reality environments in an art context.

Artists such as Char Davies moved from painting to exploring virtual space in virtual environments in the early 1990s, resulting in the works Osmose (1995) and Ephémère (1998). In Osmose, the participant, or 'immersant', must concentrate on their breath as a device to navigate vertically through the spaces represented. In Landscape, Earth, Body, Being, Space, and Time in the Immersive Virtual Environments Osmose and Ephémère (2003), Davies says that "within this spatiality, there is no split between the observer and the observed' (Davies, 2003). She argues that this is not tied to a Cartesian paradigm, but rather allows 'another way of sensing to come forward, one in which the body feels the space very much like that of a body immersed in the sea' (Davies, 2003). In this private virtual space, by: 'leaving the space of one's usual sensibilities, one enters into communication with a space that is psychically innovating ... for we do not change place, we change our nature' (Bachelard in Davies, 1997). 


\section{ARTISTIC PRACTICE IN VIRTUAL WORLDS}

Through this history of artists exploring new spaces and new technological forms this exploration has continued through sections of the artistic community that have seen the opportunity of utilising virtual worlds as a new form, or a new potential artistic space. Established real-world artists have explored virtual worlds as environments for practice. A number of artists and designers have continued to specifically work with Second Life to explore the potential and limitations of the platform, and a handful of established real world artists have seen their own concerns reflected in the Second Life space itself. In Art and the Avatar: The Kritical Works in SL Project (Doyle 2008) I concluded that there were at least two approaches that could be considered when exploring Second Life for creative practice, beyond the potential of using Second Life as a presentation space that echoes real life gallery spaces. Firstly, that Second Life was already being explored as a space for performance as the avatar could easily assume the role of the actor/performer; and secondly, that the implications for the audience as avatar were that they could become a central element in the artworks created in the space, placing the audience themselves in the position of performer (Doyle, 2008).

Of the work of artists during this initial analysis (and in particular those working on the Second Life platform) there were two broad groups of artists who were identified; those working in contemporary arts practices such as new media, or performance practice, and supported by mainstream galleries and curators, and those artists who have developed work through grass roots, self-organising and emergent practices. Lichty suggested that, although multi-user worlds had already been in existence for a number of years, it was not until the critical mass of artists was present that the emergence of New Media art in virtual worlds was 'recognised by the contemporary art curators and the mainstream art press' (Lichty, 2008). A whole range of galleries have now presented, and supported, or included artworks developed in Second Life in their gallery spaces including the Serpentine Gallery, London, the Walker Art Gallery, Liverpool, and the Eyebeam Gallery in New York, either as part of themed exhibitions or artist-focused exhibitions.

In a review of artworks created in Second Life in what could be termed the early years it is the sheer array of work created across a broad range of artistic disciplines such as art, architecture, performance, film, and media arts that was salient. From work such as Thirteen Most Beautiful Avatars (2006) by Eva \& Franco Mattes modeled on a reworking of Andy Warhol's print series, to Brian Eno's 77 Million Paintings (2007) installation recreated in Second Life, or the early Second Life music performances by Susanne Vega (2006) and Duran Duran (2006), to the politics of virtual sweatshops in Stephanie Rothenberg's Invisible Threads (2007), and finally to the inWorld projects of SL artist Angrybeth Shortbread such as Ping Space (2008), all point towards a retesting of artistic principles in virtual world spaces.

The Chinese artist Cao Fei developed a number of relevant projects including iMirror (2007), an installation and three-part documentary about Fei's avatar identity, China Tracy, which was included in the Chinese Pavilion at the Venice Biennale, and RMB City (2008-ongoing) which was presented at the Serpentine Galley, London, and in New York. Artist and filmmaker Lynn Hershman worked with Stanford University to develop Life to the Second Power (2007-ongoing), documenting and archiving two of her projects, The Dante Hotel, and Roberta Breitmore. A number of performance-based works relied on a re-enactment of historical performance art, such as Seven Easy Pieces (2005) which Marina Abramovic performed at the Guggenheim, re-enacting seven significant historical and noted Performance Art works, and Eva and Franco Mattes Synthetic Performances (2009-ongoing), and the exploration of what they term an 'imponderable medium' (Lichty 2008). The performance artist Joseph DeLappe has 


\section{Preface}

incorporated online gaming into his work since 2001 in work such as Dead_in_Iraq (2006-ongoing). In 2008 he re-enacted Mahatma Gandhi's Salt March to Dandi (2008), spending 26 days walking through Second Life using a customized treadmill that powered the movements of his inWorld counterpart, MGandhi Chakrabarti.

Other artists have found that particular combinations of the attributes of the Second Life space echo their own concerns, a notable example being the work of Paul Sermon. Sermon established a research hub in Second Life where he conducted a number of experiments such as Liberate your Avatar (2007) and Urban Intersections (2009), and more recently (in collaboration with Charlotte Gould) Mirror on the Screen (2012). Australian artist Adam Nash developed a substantial body of conceptual work in Second Life through an exploration of sound and immersive spaces. Typical of his early works is the interactive installation, or participatory artwork, A Rose Heard at Dusk (2007). Babelswarm (2008) was a group project created out of the first Australia Council Artist in Residence Award for Second Life, that brought Nash together with Christopher Dodds and Justin Clemens, to produce what was a mixed reality, realtime, interactive, audiovisual artwork (Clemens, 2008). The installation, based on the story of the Tower of Babel, captures visitors' chat text which is fed into the 'meta-babeller', which spills out words from the Second Life sky 'in strings of audiovisual letterforms' after which the words shatter on descent as the separated letters can be seen as they 'swarm in random directions seeking out other letters in order to reconstruct the word they were born in' (Nash, 2008). The artwork occupied the whole Sim that it was built on and created an interesting conceptual and abstract landscape in which to wander through or fly in.

The second category of artist working in Second Life were those who have consistently worked from within the platform itself, although there are obviously artists who are working between a supporting arts establishment and a more grass roots involvement with the space, so this divide is not so clearly defined. However, artists have emerged from the platform itself, and the Burning Life exhibitions that have been staged since 2003, initiated by the founder of Second Life, Philip Rosedale, are an important showcase for the work of such artists. An article by Jacquelyn Ford Morie, A (Virtual) World without Limits (2010), investigated artworks that have been produced primarily for a Second Life audience, and includes accounts of her experiences of installations such as Bogon Flux (2008) by artists Blotto Epsilon and Cutea Benelli and the pastoral environment Surface by artist AM Radio (Morie, 2010). Artist DC Spensley maintains an Island Sim for his hyperformalist work, and extended his artistic practice into performances such as the ZeroG Skydancers (2008) events.

In 2007 music technologist Rob Wright, known as Robbie Dingo in Second Life, produced a seminal machinima work called Watch the World (2007) utilising the Second Life space to produce the work (Au, 2007). Taking its inspiration and fundamental concept from the imaginary picture space of Van Gogh's work Starry Night (1889), Dingo explains that it was shot 'on location' in Second Life and then post-produced; 'the Sim in this work was on temporary loan so it's all been swept away now, leaving only the film behind. It was always intended however that the video would be the end product, not the build' (Dingo, 2007). There is a potency to what Dingo produced in Watch the World (2007), firstly throughout the machinima in which Dingo allows us to see the construction of this virtual, imagined space and secondly, to literally watch the artist recreate the landscape of the painting itself.

Writing again in 2011 Lichty posed the question "what happens to embodied art when the body is removed?' and proposed three aspects that contribute to the significance of virtual worlds for virtual performance art, that of Affect, Desire, and Mirroring (Lichty, 2011). The discovery of mirror neurons in the 1990s may explain the efficacy of virtual world experiences and most particularly those mediated through avatar presence. A significant work that was developed during 2009 is Becoming Dragon by 
Micha Cardenas in which she writes that the project 'is a mixed-reality performance that questions the one-year requirement of "Real Life Experience" that transgender people must fulfil in order to receive Gender Confirmation Surgery' (Cardenas, 2010). For the performance Cardenas 'lived' for 365 hours immersed in Second Life via a head mounted display and 'only seeing the physical world through a video-feed [...] during the year of research and development of this project I began my real life hormone replacement therapy' (Cardenas, 2010). Cardenas notes that both virtual worlds and biotechnology are each technologies of transformation and 'offer the promise of becoming something else, of having a new body and a new life' (Cardenas, 2010). This mixing of realities and ultimately mixing of genders in her performance piece focuses on the process of becoming and she concludes that 'the epistemological topology of becoming is shaped by the radical unknowability of the future' (Cardenas, 2010).

There have been a number of works that continue to focus on augmenting the Second Life space (often creating a strange virtual aesthetic) seen in particular in Mirror on the Screen (2012). In this project Charlotte Gould and Paul Sermon explores the concepts of presence and performance in Second Life and 'first life' and attempt to 'bridge these two spaces through mixed reality techniques and interfaces' (Gould \& Sermon, 2012). The final project to mention here is that of virtual artist Bryn Oh, Imogen and the Pigeons (2013), an immersive interactive environment built on the Immersiva Sim. The multilayered story is told through a series of poems. Writing about the closing stages of the project (that is now deleted - although documented through machinima - to make way for her new project) SL artist Bryn Oh notes that:

The story for Imogen is intended to be slightly vague as to allow the viewer to interpret the narrative with more freedom. I feel that it may be more engaging for the viewer if they are not told a definitive story which can make the viewer passive, but rather to live and interact within a story which requires them to activate their imagination (Oh, 2013).

\section{ORGANIZATION OF THE BOOK}

The book is organized into twelve chapters and arranged into four sections. A brief description of each section and each of the chapters follows:

Section 1 Creative Practices, Theoretical Contexts, Virtual Worlds establishes the initial ground of theoretical research for creative practices in virtual worlds through three chapters with a consideration of both the nature and the practices that contribute to an aesthetics of virtual environments, and opens up the discussion of the nature of virtual space for artistic enquiry.

In Chapter 1 'An Aesthetics of Digital Virtual Environments' Adam Nash examines the specificities of virtual environments as a medium for art identifying primary qualities that include visual opacity, digital colour, artificial intelligence, emergence, code, digital sound and agency. Arising from the authors own extensive art practice in virtual environments and the associated theoretical concerns he considers the technical, conceptual and ontological status of virtual environments in order to propose a formal aesthetics for art in digital environments.

In Chapter 2 'Painting Machinima in Second Life' Phylis Johnson explores the technological and artistic revolution enabled by machinima, and focuses on the rise among a community of filmmakers that express their stories and ideas through virtual worlds. Her chapter argues for machinima as a new art form through a series of case studies including that of virtual artist Bryn Oh who has the support of 


\section{Preface}

artist and fillmaker Peter Greenaway. Johnson distinguishes between the machinima concepts of game, virtual platform, and virtual worlds and describes new scholarship on its aesthetics and the cultural implications for a digital society.

In Chapter 3 'Spacing and Displacing as Artistic Enquiry' artist Taey Iohe presents a philosophical journey and practical piece of experimentation on spatiality, virtual and displacement. Taking on a themed subject her chapter explores the way in which displaced women cannot belong in either their home or a foreign land, and approaches the virtual as an unreal living space rather than an exclusively virtual environment through technology. Creating artworks in both the gallery space and the virtual space of Second Life, Iohe examines the typology and meaning of displacement through language translation and gendered practice.

Section 2 Avatar, Embodiment, Identity brings together three chapters each considering the significance of the avatar in different ways. From the first chapter that includes a study of a practice-based performance project and historical reenactment to the final two chapters that each take on the discussion of the avatar in opposing ways; one writing from the perspective of the avatar as a representation of our identity as embodied selves in virtual worlds and the other arguing that the avatar should be seen as something disembodied and that acts as a representation of loss.

In Chapter 4 'Digital Steps of Protest, Reenactment, and Networked Interaction' Natasha Chuk reviews the work of performance and protest artist Joseph DeLappe in the context of his Salt Satyagraha project that saw the artist stage a reenactment of Mahatma Gandhi's historic march in India in 1930 within the Second Life environment. Through a discussion of Walter Benjamin's concept of spielraum and Jacque Derrida's concept of the supplement she concludes that the project ends where it begins, centred on play, reenactment, and testing the complexities of a human-avatar relationship in Second Life.

In Chapter 5 'Creating a Framework to Analyse the Perception of Selfhood in Artistic Practice within Second Life' Pete Wardle draws upon existing identity theories to examine the expression of self through avatars. Through this he develops a critical framework that is then tested through the analysis of the practice of artists working with themes of identity in Second Life. Further, Wardle considers his own practice-based work in this context and examines the role artistic practice plays in changing our understanding of the way identity is expressed and perceived within virtual worlds.

In Chapter 6 'Appearance, Absence, Art: Objet A-vatar' Garfield Benjamin puts forward a model for reconceiving the avatar in terms of desire and loss and focuses on the avatar as appearance, as a negotiation of presence and absence, to reassess its role within creative practices and the construction of digital subjectivity. In spaces such as Second Life the inclusion of a representation of the subject within its own gaze shows the nature of the avatar as an always-already lost body, arguing that it demonstrates the loss inherent in all forms of embodiment.

Section 3, Found Objects, Collaborative Practices, Shared Creativity, includes three chapters that are brought together to develop the discussions around Axel Bruns key term 'produsage' as an integral element of the artistic strategies developed within the projects presented. All three chapters present research that is as a result of sustained and experimental methodologies and inventive approaches to artistic practices, and each chapter contributor takes on key theories in which to frame their research.

In Chapter 7 'Found Objects, Bought Selves' Canadian artist Lynne Heller traces the creative use of the found object collage and explores issues of appropriation and the notion of the bought self through the avatar as found object. Her practice-based research has been developed through a project series exploring the adventures of her avatar Nar Duell and Heller herself suggests the relationship between 
herself and her avatar is akin to that of a mother/daughter relationship. Heller argues, through a review of the practices of the Situationists, that an aesthetic turn in political tactics is revealed in contemporary arts practices.

In Chapter 8 'Moving Islands [Rafts]: A Collective Conglomeration in Second Life' Elif Ayiter and artist avatar Eupalinos Ugajin present the artistic processes and theoretical premises of this collaborative art project. In their text they survey the creative mechanisms and strategies of the 'metaverse', and introduce two terms, that of Bruns 'produsage' and Eno's 'unfinished artifact', that relate to the collective art process explored in the Moving Islands project. Their chapter concludes with a discussion of what they term a second order-creativity that sees the transformation of visual art works into experiential behavioural objects that become crucial components in the creation of their virtual extensions, their avatars, and the avatars domiciles.

In Chapter 9 'Meta_Body: Virtual Corporeality as a Shared Creative Process' Catarina Carneiro de Sousa presents her participatory art project and addresses what she terms the constitution of virtual corporeality as a shared creative process. The project approaches both the avatar as body/language and as such it is open to experimentation and potency, and avatar building as a shared creative process and aesthetic experience. Through a method described as 'shared creativity' three stages are presented from collective creation, to distributed creation, and finally collaborative creation.

Section 4 presents Performance Practices in Virtual Worlds and brings together both practitioners and theorists in the three chapters that consider firstly the issues surrounding digital embodiment and the status of the body in performance art, the practice of blended reality through the virtual and physical performer, and finally the ways in which SL-Bots can be explored for their aesthetic and creative potential.

In Chapter 10 " "Follow me Comrades, in to the Depths!": Body-Related Performance Art in Second Life' Maja Murnik reviews the various features of digital embodiment and considers the notion of philosopher Merleau-Ponty's 'body image' and 'body schema' in contemporary mixed and augmented reality. The chapter then examines a number of examples of body-related performance art in Second Life and particularly those that raise questions about the status of the body in the digital world itself.

In Chapter 11 'Blended Reality Performance' Joff Chafer focuses on the integration of live performance that blends both virtual and physical performers. Inspired by a 2007 Second Life artwork, Liberate your Avatar, by artist Paul Sermon, Chafer developed a number of practice-based projects in Second Life, sometimes in collaboration with artists such as Stelarc. He presents a chronological account of these projects and concludes with a discussion about the nature of this type of performance from the point of view of both the physical performers and those performing with the avatars themselves.

Finally, in Chapter 12 'SL-Bots: Automated and Autonomous Performance-Art in Second Life' authors Jeremy Turner, Michael Nixon, and Jim Bizzocchi explore the history, state-of-the-art, and interactive aesthetic potential of avatars that are designed and controlled using Artificial Intelligence in Second Life (SL-Bots). Following a discussion on the ways in which SL-Bots have been used aesthetically and creatively, they suggest ways in which SL-Bots may one day transcend their original purpose as avatarplaceholders and evolve into more complex automated aesthetic personas in themselves.

With Peter Greenaway collaborating with a number of Second Life artists (including Bryn Oh) to create a series of interactive works for an exhibition on the Golden Age of the Russian Avant-Garde in 2014 and a continued and varied range of projects in development in Second Life, this points towards a continued engagement in the opportunities the platform offers in terms of artistic practices. This volume represents the artistic and scholarly, and in many cases practice-based and practice-led research of a distinct field of research, that of the creative opportunities and artistic practices in virtual worlds. It is 
hoped that this work presented together will stimulate discussion and exchange on the nature of virtual space and the contribution that artists are making to understanding these new territories. Moreover there is still much to consider and not least to 'practice' in virtual worlds (the very nature of heuristic research itself) to uncover the nature of virtual world space and to articulate the new practices that are continuing to develop and challenge the rich field of Art and Technology.

Denise Doyle

University of Wolverhampton, UK

\section{REFERENCES}

Au, W. J. (2007) Remake the Stars. New World Notes. Available at: http://nwn.blogs.com/nwn/2007/07/ remake-the-star.html\#more

Bachelard, G. in Davies, C. (1997) Changing Space: Virtual Reality as an Arena of Embodied Being. In Packer, R. \& Jordan, K. (ed.) Multimedia: From Wagner to Virtual Reality. New York, W.W. Norton \& Company. [Online] Available at: http:///www.immersence.com

Bruns, A. (2008). Blogs, Wikipedia, Second Life, and Beyond: From Production to Produsage. New York: Peter Lang Publishing.

Cardenas, M. (2009) Becoming Dragon, Mixed-Reality Performance. Available at: http://secondloop. wordpress.com/

Cardenas, M. (2010) Becoming Dragon: A Transversal Technology Study, Code Drift: Essays in Critical Digital Studies 009. Available at: http://ctheory.net/articles.aspx?id=639

Clemens, J. (2008) Babelswarm: A real-time 3D art and audio project by Adam Nash, Christopher Dodds and Justin Clemens. Available at: http://babelswarm.blogspot.com/

Davies, C. (1995) Osmose. Virtual Reality Environment. Available at: http://www.immersence.com/ osmose/index.php

Davies, C. (1998) Ephémère. Virtual Reality Environment. Available at: http://www.immersence.com/

Davies, C. (2003). Landscape, Earth, Body, Being, Space, and Time in the Immersive Virtual Environments Osmose and Ephemere. In J. Malloy (Ed.), Women, Art and Technology. Cambridge, Massachusetts: MIT Press; Available at http://www.immersence.com

DeLappe, J. (2008) Re-enactment: The Salt Satyagraha Online. Available at: http://saltmarchsecondlife. wordpress.com/

Dingo, R. (2007) Watch the World. Machinima. Available at: http://digitaldouble.blogspot.com/2007/07/ watch-worlds.html

Dove, T., \& Mackenzie, M. (1993). Archaeology of the Mother Tongue. Virtual Reality Installation. Alberta, Canada: Banff Centre for the Arts; Available at http://www.banffcentre.ca/bnmi/coproduction/ archives/a.asp 
Doyle, D. (2008). Art and the Avatar: The Kritical Works in SL project. International Journal of Performance Arts and Digital Media, 4(2\&3), 137-153. doi:10.1386/padm.4.2_3.137_1

Eno, B. (2007) 77 Million Paintings. Exhibition. Available at: http://www.longnow.org/events/02007/ jun/29/77-million-paintings-brian-eno/

Fei, C. (2007) iMirror. Multimedia Installation. [Available at: http://blogs.walkerart.org/offcenter/2007/07/16/cao-feis-imirror/

Fei, C. (2008- ongoing) RMB City. Second Life Sim. Available at: http://www.serpentinegallery. org/2008/05/cao_fei_rmb_city.html and http://rmbcity.com/

Gould, C., \& Sermon, P. (2012) Mirror on the Screen. Available at: http://creativetechnology.salford. ac.uk/paulsermon/mirror/

Gromola, D., \& Sharir, Y. (1994). Dancing with the Virtual Dervish: Virtual Bodies. Virtual Reality Installation. Alberta, Canada: Banff Centre for the Arts; Available at http://www.banffcentre.ca/bnmi/ coproduction/archives/d.asp\#dancing

Grosz, E. (2001). Architecture From the Outside: Essays on Virtual and Real Space. Cambridge, Massachusetts: MIT Press.

Hershman, L. (2007-ongoing) Life to the Second Power (L2). Available at: http://presence.stanford. edu:3455/LynnHershman/261

Jones, D. E. (2006) I, Avatar: Constructions of Self and Place in Second Life and the Technological Imagination. Gnovis, Journal of Communication, Culture and Technology. Available at: http://gnovis. georgetown.edu

Laurel, B., \& Strickland, R. (1993). Placeholder. Virtual Reality Installation. Alberta, Canada: Banff Centre for the Arts; Available at http://www.banffcentre.ca/bnmi/coproduction/archives/p.asp\#placeholder

Lichty, P. (2008) Why Art in Virtual Worlds? E-Happenings, Relational Milieux \& "Second Sculpture". CIAC Electronic Magazine. Available at: www.voyd.com/texts/LichtySLCIACWhyVirtualArt.pdf

Lichty, P. (2011). Phantom Limbs: Affect and Identification in Virtual Performance, Panel Paper, ISEA2011. Istanbul: Sabanci University.

Macleod, D. (1996). Preface. In M. A. Moser (Ed.), Immersed in Technology: Art and Virtual Environments. Cambridge, Massachusetts: MIT Press.

Mattes, E. \& F. (2006) Thirteen Most Beautiful Avatars. Photography Exhibition. Available at: http:// www.0100101110101101.org/home/portraits/thirteen.html

Morie, J. (2010). A (virtual) world without limits: Aesthetic expression in Second Life. Journal of Gaming and Virtual Worlds, 2(2), 157-177. doi:10.1386/jgvw.2.2.157_1

Nash, A. (2007) A Rose Heard at Dusk. Available at: http://yamanakanash.net/secondlife/rose_heard_ at_dusk.html

Nash, A. (2008) Babelswarm. Available at: http://yamanakanash.net/secondlife/babelswarm.html 
Preface

Oh, B. (2013) Imogen and the Pigeons - Closing. Available at: http://brynoh.blogspot.co.uk/2013/10/ imogen-and-pigeons-closing.html

Oh, B. (2013) Imogen and the Pigeons. Available at: http://brynoh.blogspot.co.uk/2013/04/imogen-andpigeons-part-one.html

Rothenberg, S. (2008) Invisible Threads. Available at: http://www.pan-o-matic.com/projects/invisiblethreads

Sermon, P. (2007) Liberate your Avatar. Public Performance Installation. Available at: http://creativetechnology.salford.ac.uk/paulsermon/liberate/

Spensley, D. C. (2008) ZeroG Skydancers III. Online Performance. Available at: http://zerogskydancers.com/ 